\title{
Numerical modeling of batch formation in waste incineration plants
}

\author{
Karel Obroučka, Jozef Vlček, Tereza Moravcová, Veronika Blahůšková, Pavel Fojtík \\ VSB - Technical University of Ostrava, Centre for Environmental Technology 9350, 17. listopadu 15/2172, \\ Ostrava - Poruba, 708 33, Czech Republic \\ e-mail: jozef.vlcek@vsb.cz; tereza.moravcova@vsb.cz; veronika.blahuskova@vsb.cz; pavel.fojtik@vsb.cz
}

\begin{abstract}
This article is dedicated to the memory of Professor Karel Obroučka a significant Czech expert in the field of combustion waste treatment and especially a great teacher and colleague.
\end{abstract}

\begin{abstract}
The aim of this paper is a mathematical description of algorithm for controlled assembly of incinerated batch of waste. The basis for formation of batch is selected parameters of incinerated waste as its calorific value or content of pollutants or the combination of both. The numerical model will allow, based on selected criteria, to compile batch of wastes which continuously follows the previous batch, which is a prerequisite for optimized operation of incinerator. The model was prepared as for waste storage in containers, as well as for waste storage in continuously refilled boxes. The mathematical model was developed into the computer program and its functionality was verified either by practical measurements or by numerical simulations. The proposed model can be used in incinerators for hazardous and municipal waste.
\end{abstract}

Keywords: waste incineration, waste to energy, waste storage in containers, waste storage in boxes, algorithm for batch formation.

\section{INTRODUCTION}

The main factor that influences the process control of waste incinerators operation is to minimize negative impacts on the environment. The operation of waste incinerators is quite strictly defined by legislative measures ${ }^{\mathbf{1 - 2}}$. Operators of incineration plants shall ensure that combustion devices work in energy recovery modes. The condition for energy recovery of waste is that waste must be capable of burning without the support of other energy sources (fuel support), and the resulting energy must be clearly utilized. These conditions correspond with the obligations arising from the Directive of the European Parliament 76/2000/EC ${ }^{3}$ and Directive of the European Parliament 75/2010/EU ${ }^{4}$. Relatively clear terms of energy use are sometimes difficult to prove in practical terms. This fact is evident from the way which this obligation is enshrined in the Czech legislation (Annex 12 of the Law 185/2001 on waste ${ }^{1}$, as amended by later regulations).

First, it seems totally at odds with the logic that "waste to energy" refers only to municipal waste and not industrial waste/hazardous, and that the formula for calculating the energy efficiency (labeled "R1"), which was taken over by the literal translation of the Waste Framework Directive, issued by the European Parliament ${ }^{5}$, is wrong. It includes a coefficient 0.97 in the denominator (the coefficient 0.97 according to the law ${ }^{1}$ expresses the energy losses due to bottom ash and "radiation", which is also practically out of question in furnaces for municipal waste incineration). This dependence does not respect First law of Thermodynamics.

The calorific value, in particular, decides if waste is energetically used. According to the literature ${ }^{6}$, the waste is able to burn without the need of secondary energy, if its calorific value is $\mathrm{min} .5 \mathrm{MJ} \cdot \mathrm{kg}^{-1}$. The system of combustion furnace operation also affects energetic self-sufficiency of waste combustion process. At this point, the excess of combustion air is a key parameter. The authors in manuscript ${ }^{7}$ recommend the excess of combustion air during combustion of solid waste at the value 1.3. In practice, this value is usually exceeded (for municipal waste it is appropriate to burn with an excess from 1.5 to 1.6 ), which sometimes leads to unnecessary cooling of furnace working space.

Industrial and municipal waste incinerators are designed with the respect of possibility to incinerate waste of various parameters. In the case of municipal waste incineration plants, with respect to the variability of waste properties, the construction design is their requirement. Wastes are characterized by inhomogeneity and variable content of hazardous components.

The advanced optimization theories are applied to improve the monitored operating parameters of incinerators. References ${ }^{8}$ presents a model for predicting the parameters of the combustion device based on the collection and evaluation of operating variables. The key equipment of waste incinerator itself is a combustion furnace and the results of its work are mainly influenced by the composition of the batch of incinerated waste.

The work ${ }^{9}$ deals in detail the problems with modeling of process parameters on the incineration of waste as gas-solid reactions, gas flow through the porous particle bed of waste, conductive, convective, and radiative heat transfer, drying process and next parameters.

Incineration of waste batches, which are based on their random selection, do not guarantee the continuity of process. At the same time, the combustion process can become non self-sufficient and consumption of support fuel occurs. Furthermore, the varying content of pollutants in flue gases can reduce the effectiveness of their capture in flue gas cleaning system.

The work ${ }^{\mathbf{1 0}}$ presents an optimization tool for creating batches of waste incinerated with respect to achieve the maximum calorific value depending on the humidity of the incinerated waste. On line assessment of the calorific value of the incinerated waste is described in work ${ }^{\mathbf{1 1}}$. The importance of moisture of waste which influences its caloric value and subsequently parameters of combustion process is emphasized in paper ${ }^{\mathbf{1 2}}$. 
There are many reasons for which partial batches of combusted waste are needed to be form under a control choice. This can be carried out on the basis of understanding the parameters of waste destined for its incineration. The assembled batch, which parameters are the most similar to the previous batch, is specified for combustion. The next part of article presents the model for the controlled assembly of waste.

\section{MATHEMATICAL MODEL OF BATCH PRODUCTION OF INCINERATED WASTE}

The model is based on the assumption that the parameters of combustion process are balanced (their progress over time is constant or maximally changing by continuous rate) in the case if the parameters of incinerated waste batch are balanced. The proposed mathematical model creates possible combinations batches of waste from the stocks and then evaluates the parameters of these batches. For each combination of waste, an evaluating criterion $\mathrm{Kr}$ is determined. The criterion $\mathrm{Kr}$ is a dimensionless expression of conformance of the batch parameters currently compiled from the previous batch. The combination of batch that has the lowest value of $\mathrm{Kr}$ is considered to be optimal. The model evaluates the waste on basis of selected parameters (e.g. calorific value, polluting components).

The article by its content corresponds with the manuscripts ${ }^{\mathbf{1 3 - 1 4}}$ which are devoted to the evaluation criterion $K r$, and the results achieved in the project ${ }^{15}$. This paper presents the derivation of algorithms in the form in which they were subsequently implemented in the computer program. An essential part of this contribution is practical experience with the model features in operating conditions and the work is completed by numerical modeling, proving the functionality of model. The model comes in two variants, for incinerators with waste storage in containers and incinerator, in which the waste is stored in continuously replenished (released) boxes. The proposed model is time-independent. It is assumed that the waste material into the furnace is loaded in discrete batches, the frequency of batches per time unit may be arbitrary.

\section{The option of waste storage in containers}

In this case, the batch is formed by waste contained in one or more containers. In this variant, weight condition must be fulfilled (1), which is determined by performance of incinerator.

$q_{o d} \leq \sum_{j=1}^{N} m_{j} \cdot a n_{j} \leq q_{d o}$

where $q_{o d}$ is lower limit of batch weight of waste $(\mathrm{kg})$, $q_{d o}$ is upper limit of batch weight of waste $(\mathrm{kg}), m_{j}$ is weight of container content $j(\mathrm{~kg}), a n_{j}$ is variable having the value of 0 or 1 ( 1 - container is part of batch, $0-$ container is not part of batch) (1).

The basic form of evaluation criteria $K r$ (1) can be expressed as (2)

$$
K r=\left\{\sum_{i=1}^{P_{v}}{ }_{i} w \cdot\left[{ }_{i} h-\frac{\sum_{j=1}^{N}{ }_{i} \kappa_{j} \cdot m_{j} \cdot a n_{j}}{\sum_{j=1}^{N} m_{j} \cdot a n_{j}}\right]^{2}\right\} \cdot \frac{\sum_{j=1}^{N}\left(1-a n_{j}\right) \cdot\left(1+\text { urgent }_{j}\right)}{\sum_{j=1}^{N}\left(1-a n_{j}\right)}
$$

where $i$ is designation of monitored variable (1) (for example $i=1 \rightarrow$ calorific value, $i=2 \rightarrow$ sulfur content, $i=3 \rightarrow$ chlorine content), $P v$ is number of monitored thermochemical quantities (1) (in our case, $P v=3),{ }_{i} w$ is weight of variable $i\left(\mathrm{~kg}^{2} \cdot \mathrm{kJ}^{-2}\right.$ or wt. $\%^{-2}$ ) (in case of two or more variables, the weight of variable is determined by its importance in the selection process of containers), ${ }_{i} h$ is weighted average of monitored variable in the previous batch $\left(\mathrm{kJ} \cdot \mathrm{kg}^{-1}\right.$ or wt.\%) (for variable $i$ ), $m_{j}$ is weight of container content $j(\mathrm{~kg}), N$ is number of containers for waste storage (1), ${ }_{i} \varkappa_{j}$ is value of the variable $i$ in the container $j\left(\mathrm{~kJ} \cdot \mathrm{kg}^{-1}\right.$ wt.\%), urgent t $_{j}$ is variable characterizing the age of container $j(1)$.

The batch can be prepared on the basis of one or more variables (calorific value, polluting components). Their importance can be freely selected, whereas the sum of importance must be $100 \%$. The value ${ }_{i} w$ can be determined by equation (3).

${ }_{i} w=\frac{\text { priority }_{i}}{100} \cdot\left(\frac{1000}{\max _{i}}\right)^{2}$

where priority is the significance (importance) of monitored variable $i$ and reach values 0 to $100 \%(\%), \max _{i}$ is maximum value of output variable $i\left(\mathrm{~kJ} \cdot \mathrm{kg}^{-1}\right.$, wt.\%).

The value urgent solves the issue of container age. If the waste has significantly different value of set variables (calorific value, etc.) from the value of waste normally included in the batch, then it would not become part of formed batch. The equation (4) ensures the inclusion of over aged waste to the batch.

urgent $_{j}=\left[\max \left\{u_{j}-\frac{\lim i t}{\text { step }} ; 0\right\}\right]^{2}$

where $u j$ is period of container storage $\mathrm{j}(1)$, limit is time limit from which the container is considered to be old (1) (e.g. storage capacity), step is number of storage period units for which the age of container appreciably becomes evident (1) (e.g. storage capacity / 4).

\section{The option of waste storage in boxes}

The evaluation criterion for the storage of waste was proposed $\mathrm{in}^{\mathbf{1 6}}$. The equation (2) is again the basis for the interference of algorithm of batch formation for storage of waste in boxes. The difference is based on defining the mass conditions. The weight of batch $(q)$ is the sum of partial batches realized by crane grab. It is necessary to set a minimum weight of one part of waste $\left(m_{d}\right)$ with regard to the power of computer technology that performs calculations according to the proposed mathematical model. The requirement is that the weight of total batch $(q)$ is an integer multiple of $(P)$, which is in fact the number of batches by crane grab and minimum weight of one part of batch $\left(m_{d}\right)$ :

$P \cdot m_{d}=q$

where $P$ is number of batch parts (1), $q$ is required weight of batch $(\mathrm{kg}), m_{d}$ is minimum weight per one part of batch for the production of batch $(\mathrm{kg})$.

Total weight of one batch of waste for incineration $(q)$ is the sum of partial batches, which grab crane is able to dose during setting different types of waste.

At the same time:

$\sum_{j=1}^{N} m_{j}=q$ 
where $m_{j}$ is mass of waste $\mathrm{j}$ selected for batch $(\mathrm{kg}), N$ is number of boxes in storage (1).

It is also necessary to introduce the variable $P_{j}$, which indicates the number of parts of waste $j$ in batch (1).

$\sum_{j} P_{j}=P$

$m_{j}=\mathrm{P}_{\mathrm{j}} \cdot m_{d}$

By analogy with equation (2), the equation for calculation of evaluation criteria of formation the batch of incinerators with deposing waste in boxes is obtained. According to the limited number of boxes, the equation does not solve the overaged of waste. In equation (9) ${ }_{i} k_{j}$ means the presence of $i$ variable in box $j$.

$K r=\sum_{i=1}^{P_{v}}{ }_{i} w \cdot\left[{ }_{i} h-\frac{\sum_{j=1}^{N} i K_{j} \cdot P_{j} \cdot m_{d}}{q}\right]^{2}=\sum_{i=1}^{P_{v}}{ }_{i} w \cdot\left[{ }_{i} h-\frac{\sum_{j=1}^{N} K_{j} \cdot P_{j} \cdot m_{d}}{P \cdot m_{d}}\right]^{2}=$

$=\sum_{i=1}^{P_{v}}{ }_{i} w \cdot\left[{ }_{i} h-\frac{\sum_{j=1}^{N}{ }_{i} \mathrm{~K}_{j} \cdot P_{j}}{P}\right]^{2}=\min$

\section{PRACTICAL VERIFICATION OF THE PROPOSED MODEL}

The calculation of $\mathrm{Kr}$ is time-consuming, so the algorithm according to equation (2) and (9) was transcribed into a computer programming language. The program for container storage of waste from author Ferkoviče ${ }^{13}$, and the program for box storage by author Fojtík ${ }^{16}$ were used. The computer evaluates the possible combinations of waste and consequently recommends a combination that has the lowest value $K_{r}$, therefore, one that differs minimally from the previous batch.

To establish the batch of waste to be incinerated, in case of option for waste storage in boxes, it is not always necessary to examine all the combinations that satisfy the mass condition (5). It is necessary to respect the practical requirements. The criterion derived by equation (9) ideally establishes the batch of waste of same composition to be incinerated until the availability of waste involved in the batch. The computer program is used to determine the number of batches. After their implementation, the waste, which due to its different characteristics would not be chosen, will mandatory become the part of batch. Further it is also possible to specify the priority for any of waste for which an operator requires the obligation to be included in batch, for example because of its frequent occurrence. The programming solution of evaluation criteria calculation allows setting of another box, in which the stored waste is mandatory included in batch. Increasing difference in weight of total batch of waste and of waste that is its compulsory part increases the continuity of batch parameters from the previous batch.

In practical terms, the assumption of presence of over aged waste, waste with high frequency of occurrence as well as the situation of extraordinary sorting of waste to batch for other reasons. The composition of batch according to the criterion (9) will change according to occurrence of situations described above. The assembly of batch according to criteria (2 and 9) excludes the possibility of random choice of waste and realized batch is the most similar to the parameters of previous batch.

\section{Waste storage in containers}

The version of program for waste storage in containers was verified in a practical experiment on industrial waste incinerator in Frydek-Mistek. Smaller incinerator with $200 \mathrm{~kg} \cdot \mathrm{h}^{-1}$ was chosen for the experiment and $1542 \mathrm{~kg}$ of waste was prepared. During preparation of batches of incinerated waste, the emphasis was on keeping a balanced calorific value (priority $80 \%$ ), sulfur $(10 \%)$ and $\mathrm{Cl}^{-}(10 \%)$ content. The calorific value of incinerated waste ranged from 12.8 to $42.1 \mathrm{MJ} \cdot \mathrm{kg}^{-1}$. The interval is wide enough to verify the ability of model to achieve the balanced calorific values in the process. Overview of incinerated waste is in Table 1. The weight of waste in containers ranged from 5.5 to $36.5 \mathrm{~kg}$ (average $15.4 \mathrm{~kg}$, median $14.0 \mathrm{~kg}$; modus $7.0 \mathrm{~kg}$ ). With regard to the selected input conditions, it is clear that the content of container must be known in terms of mass of stored waste, the calorific value and composition. Storage capacity was 35 containers, the program simulated continuous intake of waste during the measurements, the storage was continuously supplemented by new waste, totally 100 containers were included in the database. Waste was charged into the furnace at half-hour intervals $(100 \mathrm{~kg} \pm$ $10 \%$ ), the process was evaluated for a period of 6 hours. At the beginning of measurement, the desired calorific value and the content of $\mathrm{S}$ and $\mathrm{Cl}^{-}$were estimated. Every other batch was prepared in order to achieve maximum agreement between the formed batch and the previous batch. The highest priority was assigned to calorific value. On the basis of its course, it is possible to verify the reliability of proposed mathematical model. Figure 1 shows the course of relative deviation of calculated calorific value from its desired value (calorific value of previous batch), determined by equation (10). The chart below shows the relative deviation of average calorific value of waste, which was at the moment in stock, again from the desired calorific value (previous) charge.

Table 1. Parameters of waste storage in containers

\begin{tabular}{|l|c|c|c|}
\hline \multirow{2}{*}{ Type of waste } & $\begin{array}{c}\text { Calorific } \\
\text { value } \\
\cdot \mathrm{kg}^{-1}\end{array}$ & $\begin{array}{c}\text { Content } \\
\text { of S } \\
\text { wt. } \%\end{array}$ & $\begin{array}{c}\text { Content } \\
\text { of } \mathrm{Cl}^{-}+\mathrm{F}^{-}\end{array}$ \\
\hline Oil.\% sawdust & 14982 & 0 & 0.04 \\
\hline Packing paper & 15164 & 0 & 0.04 \\
\hline Oily textile & 17459 & 0 & 0.06 \\
\hline $\begin{array}{l}\text { Plastic packing } \\
\text { I }\end{array}$ & 41351 & 0 & 0.86 \\
\hline $\begin{array}{l}\text { Plastic packing } \\
\text { II }\end{array}$ & 42116 & 0 & 0.08 \\
\hline $\begin{array}{l}\text { Paper } \\
\text { shredding }\end{array}$ & 12867 & 0 & 0.02 \\
\hline $\begin{array}{l}\text { Spruce } \\
\text { sawdust }\end{array}$ & 2356 & 0 & 0.18 \\
\hline $\begin{array}{l}\text { Paper }- \\
\text { cardboard }\end{array}$ & 13287 & 0 & 0.08 \\
\hline PET bottles & 22837 & 0.208 & 0.02 \\
\hline Textile & 20230 & 1.407 & 0.02 \\
\hline
\end{tabular}

$e=\frac{x-\mu}{\mu} \cdot 100$

where $e$ is relative difference of calorific value of assembled batch from the calorific value of required batch (dashed line on the graph), or relative deviation of average calorific value of waste in stock from the required 


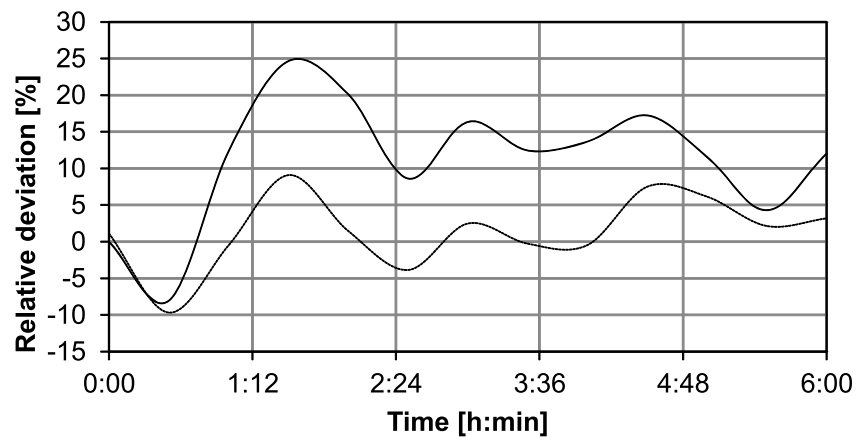

_....... assembled batch waste in stock

Figure 1. Relative deviation of calorific value

batch (solid line on the graph) (\%), $x$ is calorific value of assembled batch or the average calorific value of waste in stock $\left(\mathrm{kJ} \cdot \mathrm{kg}^{-1}\right), \mu$ is required calorific value (calorific value of previous batch) $\left(\mathrm{kJ} \cdot \mathrm{kg}^{-1}\right)$.

The deviation of calculated batch reaches lower values during the whole time of measurement in comparison with values valid for waste from which the batch was assembled. The model demonstrated the ability to create batch, which is characterized by the continuous establishment on the previous batch. The monitored deviation of actual calorific value from the required value reaches up to about $10 \%$. Changes of calorific value of stored waste occurred due to the continuous removal and registration.

The practical importance of using the model for formation of incinerated waste batches is shown in Figure 2. The calorific value is one of main factors of combustion temperature. If the balanced calorific value is monitored, the value of balanced combustion temperature can be expected. Such a combustion process is desirable, there is the reduction of support and additional fuel consumption, it helps to efficient utilization of generated waste heat and increases the efficiency of exhaust gas cleaning. Figure 2 illustrates the equilibrium temperature of reaction chamber (RC) in the post-combustion chamber (KDS).

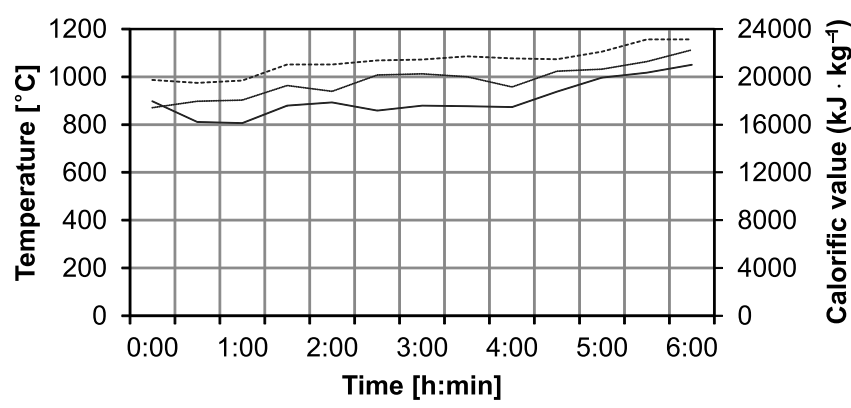

$$
\begin{aligned}
& \text { reaction chamber } \\
& \text { calorific value }
\end{aligned}
$$

Figure 2. Temperature course in the furnace area and calorific values for individual batches

The batch was made with regard to the sulfur content of waste. Figure 3 monitors the dependence of $\mathrm{SO}_{2}$ in the flue gas to the content of $\mathrm{S}$ in waste. The curve of content $\mathrm{SO}_{2}$ in the flue gas follows the trend of $\mathrm{S}$ in waste with the time delay.

\section{Waste storage in boxes}

The functionality of computer program according to the algorithm (9) was verified by numerical simulation. In this case, the model is ready for incineration with waste

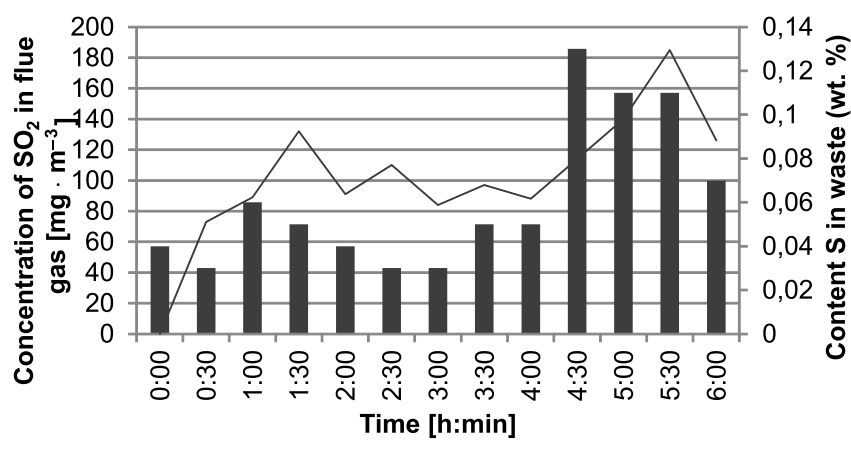

content of SO2 in the flue gas content of S in waste

Figure 3. The sulfur content of waste and the concentration of $\mathrm{SO}_{2}$ in the flue gas

storage in boxes. This variant is common for incinerators of large performance and is also typical for municipal waste incinerators. Results of long-term survey of municipal waste composition showed the variability of its parameters depending on the location from which the collection is carried out and on the season. The performance of incinerator is economically necessary to ensure continuous use of resulting waste energy and combustion system to keep the regime for energetic utilization. The requirement can be fulfilled in case that, properties of incinerated waste batches will continuously follow. Although the number of mutually distinctive groups of municipal waste is typically limited, intuitively created batch of incinerated waste cannot guarantee the continuity of process. The proposed model provides a guarantee and also gives additional user comfort to the operator. For example, the program continuously monitors the availability of storage boxes, prevents overfilling of storage box, allows preferential combustion of selected types of waste, the desired calorific value of assembled batch can be changed according to requirements of operator, otherwise its value is adjusted in the last batch.

The results of numerical simulations are given in Table 2. The initial conditions for the numerical simulation: 5 boxes for storage of waste, if the box is filled to $85 \%$ of its capacity, the waste stored there is min. $30 \%$ of batch, the waste is becoming the compulsory part of batch at least every 5 cycles, minimum proportion of waste from one box of $100 \mathrm{~kg}$, total weight $800 \mathrm{~kg}$ of batch. The batch is prepared with $100 \%$ priority of keeping the balanced calorific value. These parameters can be developed arbitrary adjusted within the developed program.

The aim of numerical simulation was to verify the functionality of program and the algorithm (9) in the model scenarios simulating the significant conditions that occur in the process conditions. During the simulation, the required calorific value changed, storage of waste was continuously monitored, and further preferential emptying of box, whose limit of filling was exceeded, occurred.

Numerical simulation shows the course of calorific value of particular batches in Figure 4 and Table 2. The graph except the curve calorific value of assembled batch by computer states the required calorific value and the average calorific value of waste, which are in stock at that moment. The curve of calculated calorific value shows few breaks. The first three batches do not reach the 
required calorific value $\left(8 \mathrm{MJ} \cdot \mathrm{kg}^{-1}\right)$ due to the fact that the mandatory part was waste from the boxes 3 and 4 , which has higher calorific value. After decrease of filling the box no. 4, waste from the box does not become part of batch and the calculated calorific value in the fourth batch got closer to the desired value. In the sixth batch, the increase of calculated calorific value occurs due to fact that the waste from the boxes 2 and 5 becomes the part of batch according to the input parameters, which was not incorporated into the batch in previous cycles. Starting with the batch no. 8 , the calculated values of calorific value agree with the required calorific values. Another change in the calculated calorific value occurs in the 22nd batch due to changes in settings where the required calorific value of batch is $9.5 \mathrm{MJ} \cdot \mathrm{kg}^{-1}$. The program adapts operatively the assembled calorific value of batch to the required value. The last insignificant deviation of calorific value of assembled batch from the required batch occurs in the cycle no. 32, when waste from the box no. 3 is mandatory for batch.

Table 2 gives the comprehensive overview of parameters of assembled batch, further documents the state of waste in stock. In the table, the black parts show the situation when the amount of waste in the box exceeds $85 \%$ of its capacity and highlight the waste which was not included in the previous batch of 5 cycles. The table shows that if one or the other conditions are fulfilled, the waste from the particular box becomes the mandatory part of batch.

\section{CONCLUSIONS}

Modern incinerators are designed with the objective of safe disposal of a wide range of waste, which often differ significantly in their composition and technical

Table 2. Results of numerical simulation of batch creation for waste storage in boxes

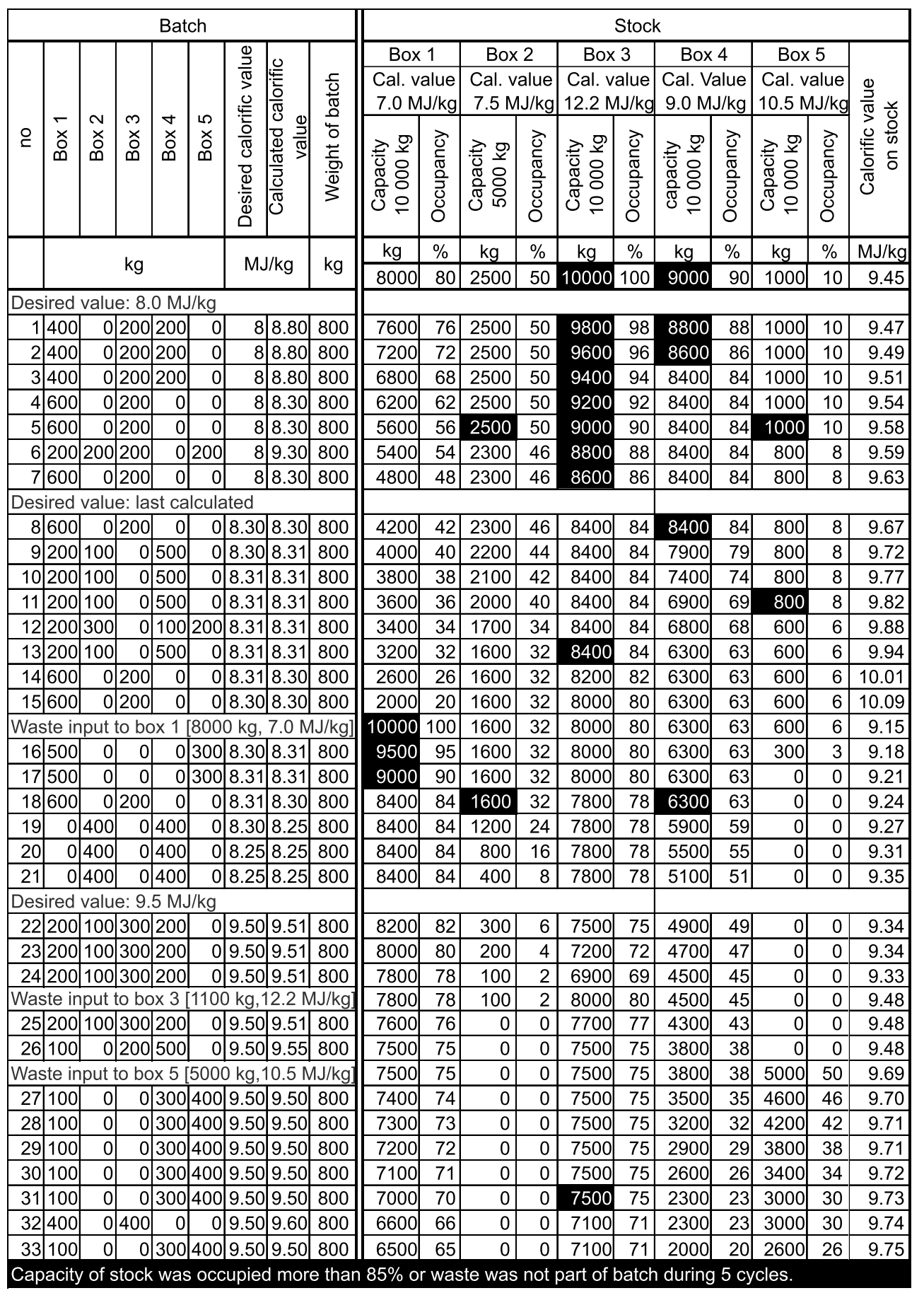




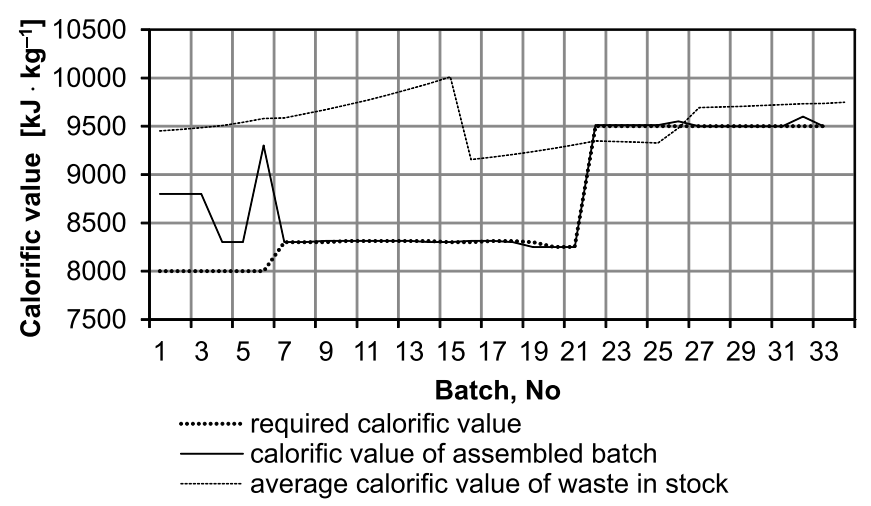

Figure 4. The course of calorific values of simulated waste batches

parameters. If the charge of incinerated waste is created intuitively, it does not guarantee that the combustion process will be balanced according to the development of technical parameters. Technical parameters of the process are characterized by their frequent changes. The present numerical model allows controlled formation of the charge of incinerated waste. The controlling criteria for the creation of the charge are the calorific value of waste and content of pollutants while the user selects the importance of these criteria. The numerical model creates the charge of waste that follows the previous charge maximally by selected properties (calorific value, content of contaminants). It guarantees the continuity of the process and the alignment of the calorific value of the incinerated waste creates the conditions for a balanced production of heat or electricity and the efficient flue gas cleaning is possible based on continuity of contaminant in the waste. The accuracy of the model for waste incineration plants with waste container storage was verified by operational measurements and numerical simulations were verified for correct operation of waste incineration with waste storage pits. Practical verification as well as numerical simulations proved the proper functionality of proposed model.

\section{ACKNOWLEDGMENT}

This work was financially supported by the Ministry of Education, Youth and Sports of the Czech Republic in the "National Feasibility Program I", project LO1208 "Theoretical Aspects of Energetic Treatment of Waste and Environment Protection against Negative Impacts".

\section{LITERATURE CITED}

1. Act No 185/2001 Coll., on waste (Czech waste Act).

2. Decree of the Czech Ministry of the Environment No 415/2012 Coll., on permissible level of pollution and the discovery and implementation of certain other provisions of the Clean Air Act (emission regulation).

3. Directive of the European Parliament and of the Council (EC) 76/2000, on incineration of waste.

4. Directive of the European Parliament and of the Council (EU) 75/2010, on industrial emissions.

5. Directive of the European Parliament and of the Council (EC) 98/2008, on waste.

6. Bilitewski, B., Härdtle, G. \& Marek, K. (1994). Waste Management. Berlin Heidelberg, Germany: Springer-Verlag. ISBN: 3-540-59210-5.

7. Miyagoshi, Y., Tatefuku, T. \& Nishino, M., et al. (2004). Advantageous effects of low air ratio combustion in an advanced stoker-type waste incinerator. Report from Second International Conference on Waste Management and the Environment, 29 September-1 October 2004 (pp. 155-164). Rhodos, Greece: Waste Management in Japan.

8. Leskens, M., van Kessel, L.B.M. \& Bosgra, O.H. (2005). Model predictive control as a tool for improving the process operation of MSW combustion plants. Waste Manag.25(8), 788-798. DOI: 10.1016/j.wasman.2005.03.005.

9. Asthana, A., Menard, Y., Sessiecq, P. \& Patisson, F. (2010). Modeling On-Grate MSW Incineration with Experimental Validation in a Batch Incinerator. Industrial \& Engineering Chem. Res. 49(16), 7597-7604. DOI: 10.1021/ie100175e.

10. Gebreegziabher, T., Oyedun, A.O., Lam, K.L., Lee, H.K.M. \& Hui, C.W. (2012). Optimization of MSW Feed for Waste to Energy Practices. Report from $15^{\text {th }}$ International Conference on Process Integration, Modelling and Optimisation for Energy Saving and Pollution Reduction, 25-29 August 2012 (pp. 679-684). Prague, Czech Republic: Chem. Engine. Transact. DOI: 10.3303/CET1229114.

11. Van Kessel, L.B.M., Leskens, M. \& Brem, G. (2002). On-line calorific value sensor and validation of dynamic models applied to municipal solid waste combustion. Transactions in IchemE 80(B5), 245-255, DOI: 10.1205/095758202762277605.

12. Pershing, D.W., Lighty, J.S., Silcox, G.D., Heap, M.P. \& Owens, W.D. (2007). Solid waste incineration in rotary kilns. Comb. Sci. Technol. 93(1-6), 245-276. DOI: 10.1080/00102209308935292.

13. Obroučka, K. \& Ferkovič, J. (2005). Optimization of batch production for waste incineration. Acta Metall.Slovaca, No 1, 251-257. ISSN 1335-1532. (in Czech).

14. Byczanski, P. \& Obroučka, K. (2007). The proposal of mathematical model to optimize the formation of mixtures of combustible waste for incineration. Chem. Pap. No 8, V. 101, 668-672. ISSN 1213-7103.

15. Obroučka, K. et al. (2012). Report on the implementation of the project of Ministry of Industry and Trade, Permanent Prosperity No 2A-3TP1/087 solved in 2008-2011 Research on process technology and design optimization of incinerators for municipal waste, providing an increase in energy conversion efficiency. Final Report. I. part VŠB - TU Ostrava, Centre of environmental technologies. (in Czech).

16. Fojtík, P. (2010). Specification of algorithm to optimize the furnace and the development of software components for visualizing the results of optimization process. (Program of waste storage in boxes.) Partial report on the project of Ministry of Industry and Trade No 2A-3TP1/087, VŠB - TU Ostrava. (in Czech). 